\title{
Effect of Magnesium on the Mechanical and Bioactive Properties of Biphasic Calcium Phosphate
}

\author{
Ponnusamy Kanchana, Chinnathambi Sekar \\ Department of Bioelectronics and Biosensors, Alagappa University, Karaikudi, India \\ Email: Sekar2025@gmail.com
}

Received August 12, 2012; revised September 15, 2012; accepted September 25, 2012

\begin{abstract}
Incorporation of trace elements into calcium phosphate structure is of great interest for the development of artificial bone implants. Biphasic calcium phosphate (BCP) composed of hydroxyapatite (HA) and $\beta$-tricalcium phosphate $(\beta$-TCP) have been synthesized in the presence of magnesium (5 M\% - $20 \mathrm{M} \%$ ) by gel method under physiological conditions. Crystallization of Mg-BCP in the gel medium mimics the Mg intake in the human body. Powder X-ray diffraction and Fourier transform infrared analyses confirmed that the Mg doping leads to the enrichment of $\beta$-TCP phase and suppresses the HA content in BCP. Nanoindentation studies indicate a significant decrease in hardness and elastic modulus values of $\mathrm{BCP}$ due to $\mathrm{Mg}$ doping. In vitro bioactivity study has confirmed the formation of apatite layer on the $\mathrm{Mg}$ doped samples making it suitable for bone replacement. The results suggest that the optimum Mg doping promotes the bioactivity which is perquisite for biomedical applications.
\end{abstract}

Keywords: Biphasic Calcium Phosphate; Crystal Growth; X-Ray Diffraction; Mechanical Properties

\section{Introduction}

Biphasic calcium phosphate (BCP) composed of a mixture of hydroxyapatite $\left(\mathrm{HA}, \mathrm{Ca}_{10}\left(\mathrm{PO}_{4}\right)_{6}(\mathrm{OH})_{2}\right)$ and $\beta$-tricalcium phosphate $\left(\beta\right.$-TCP, $\beta$ - $\left.\mathrm{Ca}_{3}\left(\mathrm{PO}_{4}\right)_{2}\right)$ are interesting candidates in reconstructive surgery [1-3]. They are particularly suitable for synthetic bone substitution applications because the HA provides a permanent scaffold for new bone formation via osteoconduction and the resorption of the $\beta$-TCP oversaturates the local environment with $\mathrm{Ca}^{2+}$ and $\mathrm{PO}_{4}^{3-}$ ions to accelerate this new bone formation. The HA $/ \beta$-TCP ratio dominantly determines the rate and extent of BCP resorption in vivo, in that higher $\beta$-TCP contents allow faster and more extensive resorption [4]. Magnesium, one of the most important divalent ions associated with the biological apatite, has its own significance in the calcification process and on bone fragility and has indirect influence on mineral metabolism. BCP with $\mathrm{Mg}$ incorporation has been the subject of extensive research because of its potential for developing artificial bone and other biomedical applications [5]. The amount of HA and $\beta$-TCP in $\mathrm{BCP}$ can be tailored by the insertion of $\mathrm{Mg}$. Independently, $\mathrm{Mg}$ doped HA is of great interest for the development of artificial bones. The presence of $\mathrm{Mg}^{2+}$ within HA lattice sensibly affects apatite crystallization in solution promoting the formation of $\beta$-TCP and thus forming $\mathrm{BCP}$ [6].

Several methods have been reported to prepare $\mathrm{Mg}$ substituted HA, $\beta$-TCP and BCP [6-9]. Ryu et al. [7] showed that the MgO-doped $\mathrm{HA} / \beta$-TCP synthesized by conventional solid state reaction method exhibited high density and improvements in compressive strength and fracture toughness. In particular, the compressive strength shows $1203 \mathrm{MPa}$, which is three times greater than the undoped HA/ $\beta$-TCP composite. Gomes et al. [1] have reported that the bioactivity of the $\mathrm{BCP}$ has improved due to the presence of $\mathrm{Mg}$ atoms in the structure of the $\beta$-TCP phase. Kannan and Ferreira [8] have reported that the sodium, magnesium and fluorine co-substituted HA/ $\beta$-TCP composites have higher thermal stability upto $1400^{\circ} \mathrm{C}$. In general, sol-gel and precipitation methods need high temperature heating to produce $\mathrm{BCP}$ phases, and the high temperature treatments results in the formation of minor phases such as $\mathrm{CaO}$ and $\mathrm{MgO}$ [1].

Earlier we have demonstrated that the strontium $(\mathrm{Sr})$ doped BCP synthesized by gel method was free from these impurities [10]. As the gel medium offer the possibility to mimic the growth of various biominerals in environments similar to natural biomineralization [11,12], we have carried out the synthesis of BCP in sodium metasilicate gel with various concentration of magnesium. Effect of $\mathrm{Mg}$ addition on the HA/ $\beta$-TCP ratio, morphology, bioactive properties and mechanical behavior of $\mathrm{BCP}$ have been investigated.

\section{Materials and Method}

$\mathrm{BCP}$ was prepared by gel method using AR grade re- 
agents. Single diffusion gel method was employed to prepare $\mathrm{BCP}$ using sodium metasilicate (SMS,

$\mathrm{Na}_{2} \mathrm{SiO}_{3} \cdot 9 \mathrm{H}_{2} \mathrm{O}$ ) gel. The gel was prepared by mixing SMS solution of specific gravity $1.03 \mathrm{~g} / \mathrm{cm}^{3}$ and $0.6 \mathrm{M}$ of disodium hydrogen phosphate $\left(\mathrm{Na}_{2} \mathrm{HPO}_{4}\right)$ in the ratio $1: 1$. The $\mathrm{pH}$ of the solution was adjusted to 7.4 using $10 \%$ glacial acetic acid. About $10 \mathrm{ml}$ of this solution was allowed to gel in a test tube over a period of 2 days. After the gelation, $1 \mathrm{M}$ anhydrous $\mathrm{CaCl}_{2}$ solution was poured on the gel without disturbing it. Growth experiments were carried out at room temperature for a period of three weeks. Finally, samples were harvested by decanting the test tubes and the gel was removed by washing. The samples were kept in hot air oven $\left(60^{\circ} \mathrm{C}\right)$ for 2 hours. In another series, supernatant solution was prepared by mixing $1 \mathrm{M}$ of anhydrous $\mathrm{CaCl}_{2}$ with $0.05,0.1,0.15$ and $0.2 \mathrm{M}$ of magnesium chloride $\left(\mathrm{MgCl}_{2} \cdot 2 \mathrm{H}_{2} \mathrm{O}\right)$ and the growth was carried out as described above. BCP crystallites collected from middle layers of each test tube were subjected to systematic studies to understand the role of $\mathrm{Mg}$ on the growth and mechanical properties. Both the pristine and $\mathrm{Mg}$ doped $\mathrm{BCP}$ were sintered at $1000^{\circ} \mathrm{C}$ in ambient atmosphere for 5 hours and the resulting powders were characterized by commonly used techniques.

Powder X-ray diffraction pattern was recorded on Bruker AXS D8 advanced diffractometer within the $2 \theta$ range of 10 to $55^{\circ}$ using $\mathrm{CuK} \alpha 1$ as $\mathrm{X}$-ray source $(\lambda=$ $1.5406 \AA$ ). Surface analyses were carried out on BCP samples using scanning electron microscopy (SEM) JSM 5610 LV JEOL make. Elemental analyses were done using the OXFORD INCA energy dispersive X-ray spectrometer (EDX) attached to SEM. Thermogravimetry of samples was performed using TA instruments SDT Q600 V8.3 in the temperature range of $30^{\circ} \mathrm{C}-1200^{\circ} \mathrm{C}$ at the heating rate of $20^{\circ} \mathrm{C} /$ minute in nitrogen atmosphere. FTIR spectra were recorded on a Perkin Elmer (Spectrum RXI) spectrometer in transmission mode in the wave number range between 400 and $4000 \mathrm{~cm}^{-1}$ using $\mathrm{KBr}$ pellets.

To test the in vitro bioactivity, the samples were immersed in simulated body fluid (SBF). The SBF was prepared according to the procedure described by Kokubo [13]. Samples were pressed into pellets of about 8 $\mathrm{mm}$ diameter and $1 \mathrm{~mm}$ thickness and the pellet was immersed in $15 \mathrm{ml}$ of SBF solution in airtight plastic container. The solution was renewed every $48 \mathrm{~h}$ for a period of three weeks. Then the samples were taken out, washed with deionized water and dried. The morphological variation of the pellets surface after soaking in SBF was studied by SEM.

For characterizing the mechanical response, both pristine and $\mathrm{Mg}$ doped $\mathrm{BCP}$ were die-pressed and sintered at $600^{\circ} \mathrm{C}$ for $5 \mathrm{~h}$ in ambient atmosphere. Indentation impressions were made by nanobased indentation system
NHTXS/S: 50-0172 with diamond Berkovich indenter. The force used for all the samples was $100 \mathrm{mN}$ with loading and unloading rate of $20 \mathrm{mN} / \mathrm{min}$. A minimum of 10 indents were made on each sample. Distance between two separate indents was more than $20 \mu \mathrm{m}$ to avoid the influence of residual stresses from adjacent impressions. From the load $(P)$-penetration depth $(h)$ curves, the shape of the unloading curve can be used as a means of obtaining the elastic properties and hardness of the sample. The slope $S$ is the initial unloading stiffness, $A$ is the projected area of contact and $E_{r}$ is the reduced modulus determined by a method that has been developed and described by Oliver and Pharr [14].

$$
\begin{aligned}
& S=\frac{\mathrm{d} P}{\mathrm{~d} h}=\frac{2}{\sqrt{\pi}} E_{r} \sqrt{A} \\
& \text { (or) } E_{r}=\frac{\sqrt{\pi}}{2} \frac{S}{\sqrt{A}}
\end{aligned}
$$

The elastic modulus of the sample $E_{s}$ can be calculated using the relation

$$
\frac{1}{E_{r}}=\frac{\left(1-v_{s}^{2}\right)}{E_{s}}+\frac{\left(1-v_{i}^{2}\right)}{E_{i}}
$$

where $E_{i}$ is elastic modulus of the indenter tip, $v_{s}$ and $v_{i}$ are the Poisson ratio of the sample and indenter tip respectively. The hardness $(H)$ which is defined as the mean pressure that the material will support under load is determined by the following relation

$$
H=\frac{P_{\max }}{A}
$$

where $P_{\max }$ is the maximum applied load.

\section{Result and Discussion}

\subsection{Synthesis of BCP}

Biphasic calcium phosphate consisting of HA and $\beta$-TCP was successfully synthesized by gel method. Upon the addition of $\mathrm{CaCl}_{2}$ solution on the top of the set gel in the test tubes, $\mathrm{Ca}^{2+}$ diffuses into the gel and reacts with $\mathrm{PO}_{4}^{3-}$ producing white precipitate at the gel solution interface. Just below this, a circular white disc was observed after one day. Subsequently, 12 discs of about 3 $\mathrm{mm}$ thickness each have grown in the gel medium over a period of three weeks. The space between successive white discs was found to increase towards the bottom of the test tube from the interface due to the lack of diffusion of "Ca" from top of the gel down to the bottom of the tube. These white colored circular discs, commonly known as Liesegang rings, were identified as BCP (Figure 1(a)).

In $\mathrm{Mg}$ added experiments, Liesgang rings have appeared 4 to 5 days after the addition of supernatant solu- 


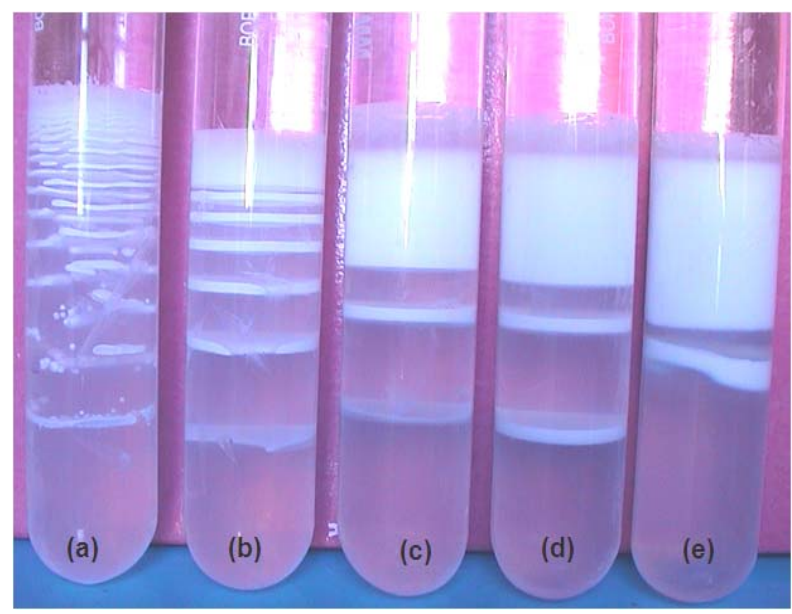

Figure 1. BCP in the form of Liesegang rings (a) undoped BCP; (b) $0.05 \mathrm{M}$; (c) $0.1 \mathrm{M}$; (d) $0.15 \mathrm{M}$; and (e) $0.2 \mathrm{M} \mathrm{Mg}$ doped BCP.

tion which indicate that the initial nucleation and growth rate were retarded due to the presence of $\mathrm{Mg}$ in the growth environment. The number of white discs got decreased as the concentration of $\mathrm{Mg}(0.05-0.2 \mathrm{M})$ increased in the supernatant solution (Figures 1(b)-(e)). We could collect the products grown with 0.05 and 0.1 $\mathrm{M} \mathrm{Mg}$ only. The white discs formed at higher Mg levels $(0.15$ and $0.2 \mathrm{M})$ were very fragile and got mixed up with the gel at the time of harvest. It should be noted that the amount of $\mathrm{Ca}$ present in the growth environment remained the same as that of pristine $\mathrm{BCP}$ and $\mathrm{Mg}$ was added as additive only. Thus the presences of $\mathrm{Mg}$ seem to inhibit the formation of BCP. This inhibitory effect may be attributed to the incorporation of smaller $\mathrm{Mg}^{2+}$ $(0.66 \AA ̊)$ at larger $\mathrm{Ca}^{2+}$ site $(1.00 \AA \AA)$ [15]. The presence of strontium $\left(\mathrm{Sr}^{2+}, 1.13 \AA\right)$ in the growth environment is also known to inhibit the formation of BCP [10]. Compared to $\mathrm{Sr}^{2+}$, the $\mathrm{Mg}^{2+}$ has a strong influence on the growth rate and total yield of BCP. The solubility of the ionic impurity in the mother solution has been considered as an indicator of the strength of the interfacial coordination, the highest solubility corresponding to the weakest interaction [16]. The addition of $\mathrm{MgCl}_{2} \cdot 2 \mathrm{H}_{2} \mathrm{O}$ with relatively high solubility affects the solubility of the growth environment. Thus the $\mathrm{Mg}$ addition seems to inhibit the less soluble HA growth and lead to the formation of initial transient phases such as TCP [17]. In both pure and $\mathrm{Mg}$ added growth experiments $(0.05,0.1 \mathrm{M} \%)$, DCPD crystals $\left(\mathrm{CaHPO}_{4} \cdot 2 \mathrm{H}_{2} \mathrm{O}\right)$ have grown in between the rings. No such crystals were found at higher concentration of Mg. Bigi et al. [18] also found significant inhibition by $\mathrm{Mg}^{2+}$ on DCPD crystals.

\subsection{Powder XRD Analyses}

The as prepared $\mathrm{BCP}$ (undoped) and $\mathrm{Mg}-\mathrm{BCP}$ ( $\mathrm{Mg}$ doped $\mathrm{BCP}$ ) samples were identified as a mixture of HA and $\beta$-TCP (Figures 2(a) and (b)) in agreement with the JCPDS standards (09-0169 for $\beta$-TCP and 09-0432 for $\mathrm{HA})$. For Mg-BCP, XRD peaks corresponding to $\beta$-TCP planes $(0210,110)$ were found to be highly intensed and the planes $\left(\begin{array}{lll}2 & 1 & 1\end{array}\right)$ corresponding to HA was less intensed. Contrary to the $\mathrm{BCP}, \mathrm{Mg}$ doping enriches $\beta$-TCP content and suppresses the HA formation. A number of ions are known to inhibit and disrupt nucleation of Ca-P phases. Salimi et al. [19] showed that the $\mathrm{Mg}^{2+}$ has a marked inhibiting effect on HA growth. They attributed the inhibitory effect of $\mathrm{Mg}^{2+}$ to its adsorption at active growth sites. This kinetically hinders nucleation of HA. In our earlier work, we found that the $\mathrm{Sr}^{2+}$ doping has enhanced the formation of HA and reduced the $\beta$-TCP content in the BCP composites which was attributed to the difference in ionic size of the dopant $\operatorname{Sr}^{2+}(1.13 \AA)$ in place of $\mathrm{Ca}^{2+}(1.00 \AA)$.

High temperature annealing $\left(1000^{\circ} \mathrm{C}\right)$ of pristine $\mathrm{BCP}$ resulted in the occurrence of more distinct and sharp XRD peaks of $\beta$-TCP (Figures 3(a) and (b)). Contrary to this, Mg-BCP samples have mainly $\beta$-TCP with traces of $\gamma-\mathrm{Ca}_{2} \mathrm{P}_{2} \mathrm{O}_{7}$ phase. Further, the XRD peaks of the $\mathrm{Mg}$ doped samples have been slightly and continuously shifted to higher diffraction angles and there was a slight decrease in their peak intensity (see inset of Figure 3). Table 1 shows the variation of lattice parameters of the investigated samples. These results suggest that $\mathrm{Mg}$ is preferentially incorporated into the $\beta$-TCP phase, the replacement of $\mathrm{Ca}$ by $\mathrm{Mg}$ induces lattice contraction and the respective displacement toward higher $2 \theta$ angles [7]. Gomes et al. [1] reported the occurent of minor impurity phases $\mathrm{CaO}, \mathrm{CaCO}_{3}$ and $\mathrm{MgO}$ in the pristine and $\mathrm{Mg}$ $\mathrm{BCP}$ samples sintered at high temperature $\left(500^{\circ} \mathrm{C}\right.$ -

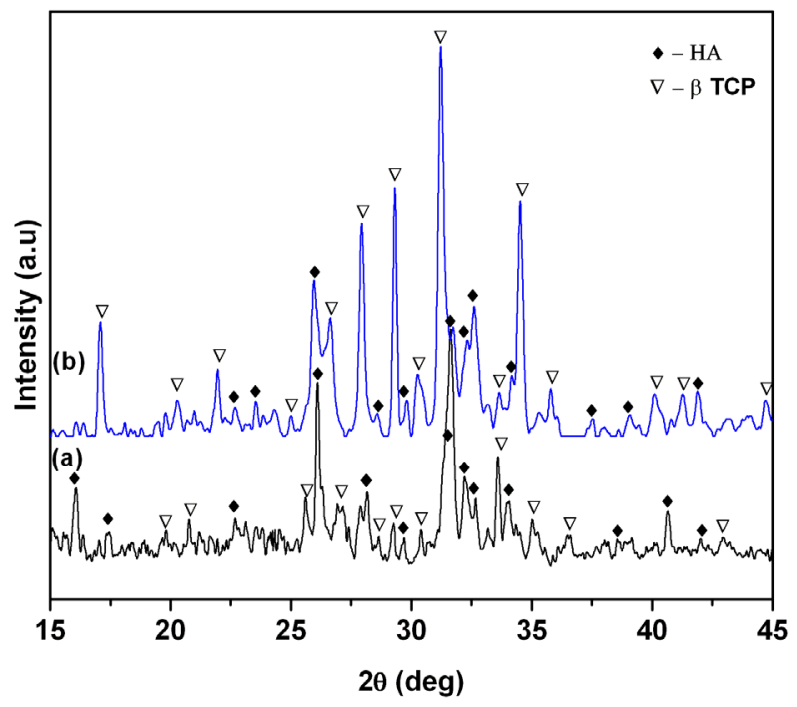

Figure 2. XRD patterns of (a) pure BCP and (b) $0.1 \mathrm{M} \mathrm{Mg}$ doped BCP. 


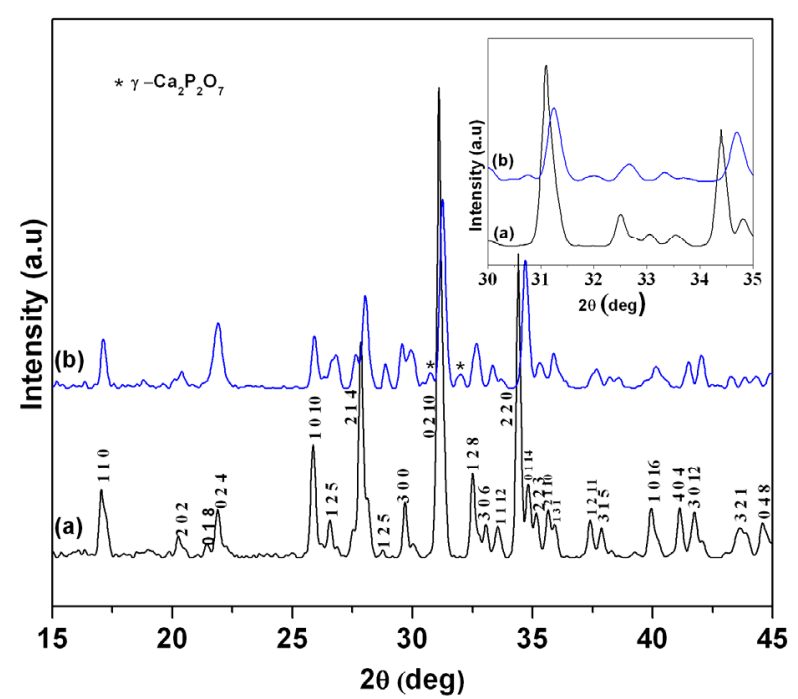

Figure 3. XRD patterns of sintered $\left(1000^{\circ} \mathrm{C}\right)$ (a) pure BCP and (b) 0.1 M Mg doped BCP. Inset figure shows a systematic shift towards the higher angle side ( $2 \theta$ values between $30^{\circ}$ to $35^{\circ}$ ).

Table 1. Lattice parameters of pure and Mg doped $\beta$-TCP $\left(1000^{\circ} \mathrm{C}\right)$.

\begin{tabular}{cccc}
\hline \multirow{2}{*}{ Samples } & \multicolumn{2}{c}{ Lattice parameters $(\AA)$} & Volume $\left(\AA^{3}\right)$ \\
\cline { 2 - 3 } & $a$ & $c$ & \\
\hline$\beta$-TCP & 10.4147 & 37.2776 & 3501.57 \\
$\beta-\mathrm{TCP}+0.1 \mathrm{M} \mathrm{Mg}$ & 10.3408 & 37.1926 & 3444.17 \\
\hline
\end{tabular}

$1100^{\circ} \mathrm{C}$ ). In the present case, both the as prepared and sintered $\left(1000^{\circ} \mathrm{C}\right)$ samples synthesized by gel method did not indicate the presence of any such impurity phases up to the resolution limit of the XRD measurement.

\subsection{SEM- EDX Analyses}

Define abbreviations and acronyms the SEM pictures of the pure and $0.1 \mathrm{M} \mathrm{Mg-BCP}$ samples are shown in Figures 4(a) and (b). The micrograph of BCP consisted of fibers with an anisotropic aspect of approximately $6-10$ $\mu \mathrm{m}$ in length and $0.5-1.0 \mu \mathrm{m}$ in width (Figure 4(a)). The Mg-BCP consisted of agglomerates of fibers on the surface (Figure 4(b)), which confirmed that the presence of $\mathrm{Mg}$ changed the growth pattern. An in vitro bioactivity test of pure and $0.1 \mathrm{M} \mathrm{Mg-BCP}$ samples are shown in Figures 4(c) and (d). Mg-BCP has revealed the formation of apatite layer on the surface of the pellets when compared to that of pure BCP. The newly formed apatite layer consisted of tiny spherical particles of calcium phosphates (Figure 4(d)). This is in accordance with the fact that a bioactive material would form a layer of apatite between bones and implant which helps in bonding of the implant to bone [13].

EDX measurements were made at different points on

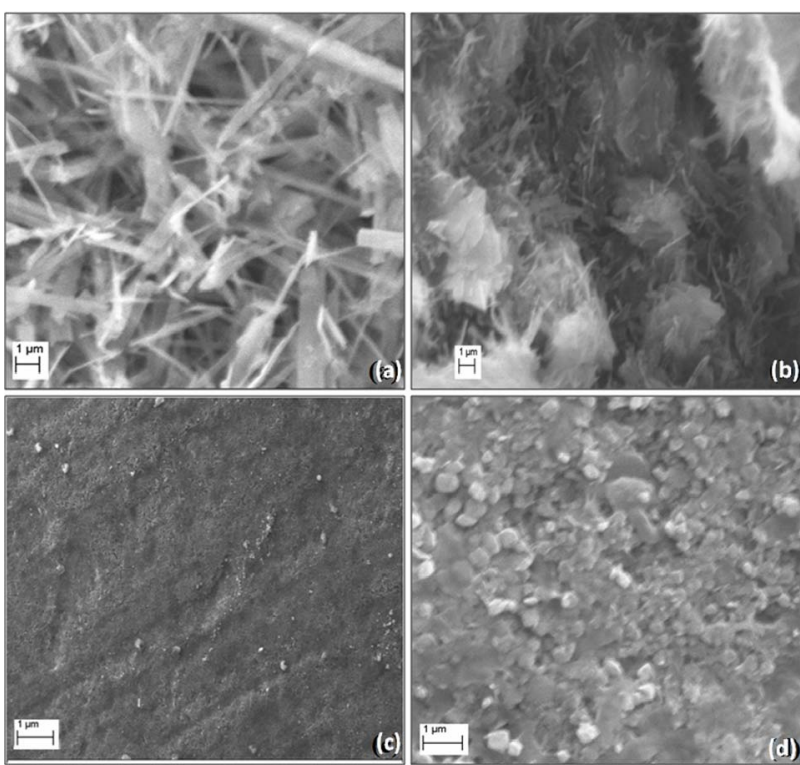

Figure 4. SEM pictures of (a) pure BCP; (b) $0.1 \mathrm{M} \mathrm{Mg}$ doped BCP and SBF soaked samples of (c) pure BCP (d) 0.1 $M$ Mg doped BCP.

the samples and the results show that the $\mathrm{BCP}$ is primarily composed of calcium and phosphorus without the presence of other impurities (Figures 5(a) and (b)). In $\mathrm{BCP}$, the $\mathrm{Ca} / \mathrm{P}$ ratio was found to be 1.58 [20]. In $\mathrm{Mg}-\mathrm{BCP},(\mathrm{Ca}+\mathrm{Mg}) / \mathrm{P}$ ratio was estimated at 1.42 . The average atomic percentages of the individual elements are shown in Table 2. It can be noticed that the addition of $\mathrm{Mg}$ leads to the " $\mathrm{Ca}$ " reduction when compared to $\mathrm{BCP}$ sample. The average $\mathrm{Mg}$ value in the $0.1 \mathrm{M}$ $\mathrm{Mg}-\mathrm{BCP}$ was estimated to be $3.52 \mathrm{~atm} \%$.

\subsection{Thermogravimetric Analyses}

TG curves of BCP and Mg-BCP are shown in Figure 6. In both the cases, initial weight loss up to $\approx 450^{\circ} \mathrm{C}$ was due to the loss of adsorbed water (up to $200^{\circ} \mathrm{C}$ ) and lattice water (up to $450^{\circ} \mathrm{C}$ ) [21]. Above this, weight loss occurred in several steps between $450^{\circ} \mathrm{C}$ and $900^{\circ} \mathrm{C}$ which indicate the transformation of HA into $\beta$-TCP phase in the BCP [22].

The total weight loss up to the measured temperature of $1200^{\circ} \mathrm{C}$ was found to be $10.02 \%$ and $12.02 \%$ respectively for pristine and $\mathrm{Mg}$ doped $\mathrm{BCP}$. In addition, a slight decrease in the decomposition temperature for $\mathrm{Mg}$ doped sample was observed in the TG curve. These observations suggest that the $\mathrm{Mg}$ doping lead to the reduced thermal stability of BCP.

\subsection{FTIR Analyses}

The FTIR spectra of $\mathrm{BCP}$ and $\mathrm{Mg}-\mathrm{BCP}$ show vibrational bands characteristic of calcium phosphate compounds (Figure 7). The band at $1031 \mathrm{~cm}^{-1}$ is assigned to the tri- 
Table 2. EDX data of pure and Mg doped BCP.

\begin{tabular}{ccc}
\hline Element & Pure BCP (atm. \%) & Mg doped BCP (atm. \%) \\
\hline $\mathrm{Ca}$ & 61.25 & 55.18 \\
$\mathrm{P}$ & 38.75 & 41.30 \\
$\mathrm{Mg}$ & - & 3.52 \\
& $\mathrm{Ca} / \mathrm{P}=1.58$ & $(\mathrm{Ca}+\mathrm{Mg}) / \mathrm{P}=1.42$ \\
\hline
\end{tabular}

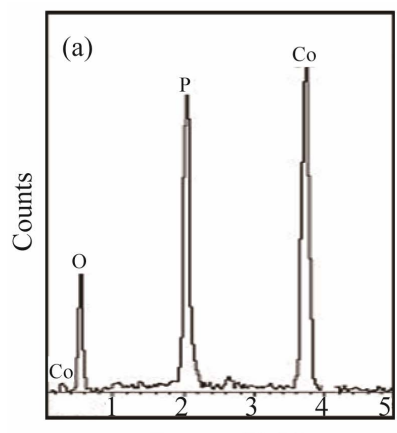

Energy $(\mathrm{KeV})$

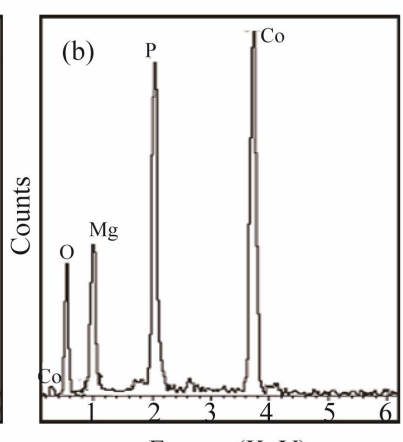

Energy $(\mathrm{KeV})$
Figure 5. EDX spectra of (a) BCP and (b) $0.1 \mathrm{M}$ Mg doped BCP.

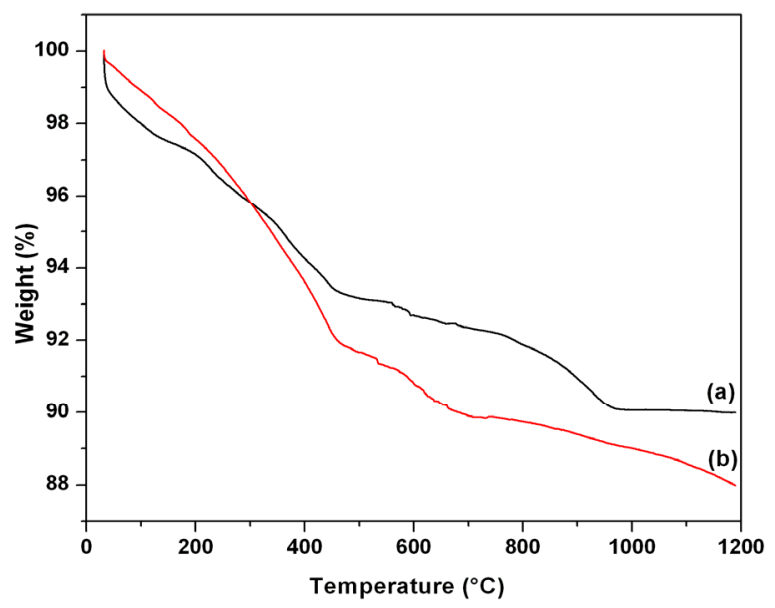

Figure 6. TG curves of (a) BCP and (b) $0.1 \mathrm{M} \mathrm{Mg}$ doped BCP.

ply degenerate $v_{3}$ asymmetric P-O stretching mode. The peak at $961 \mathrm{~cm}^{-1}$ is attributed to $v_{1}$, the non-degenerate $\mathrm{P}-\mathrm{O}$ symmetric stretching mode. The peaks at 601 and $562 \mathrm{~cm}^{-1}$ correspond to the triply degenerate $v_{4}$, O-P-O bending mode and the band at $460 \mathrm{~cm}^{-1}$ is attributed to the doubly degenerate $v_{2}$, O-P-O bending mode. The bands at 1640 and $3441 \mathrm{~cm}^{-1}$ are assigned to the adsorbed water [23]. The low intensity hydroxyl group at $3553 \mathrm{~cm}^{-1}$ indicates the presence of HA/TCP [24]. The low intensity $\mathrm{OH}^{-}$group at $3553 \mathrm{~cm}^{-1}$ of the $\mathrm{BCP}$ was not visible in the case of $\mathrm{Mg}-\mathrm{BCP}$ sample. Moreover, broadening of phosphate band at $1000-1100 \mathrm{~cm}^{-1}$ and the weak bands at $869,1371 \mathrm{~cm}^{-1}$ due to the $\mathrm{P}-\mathrm{O}(\mathrm{H})$ stretching in $\mathrm{HPO}_{4}^{2-}$ groups have appeared in the $\mathrm{Mg}$ -

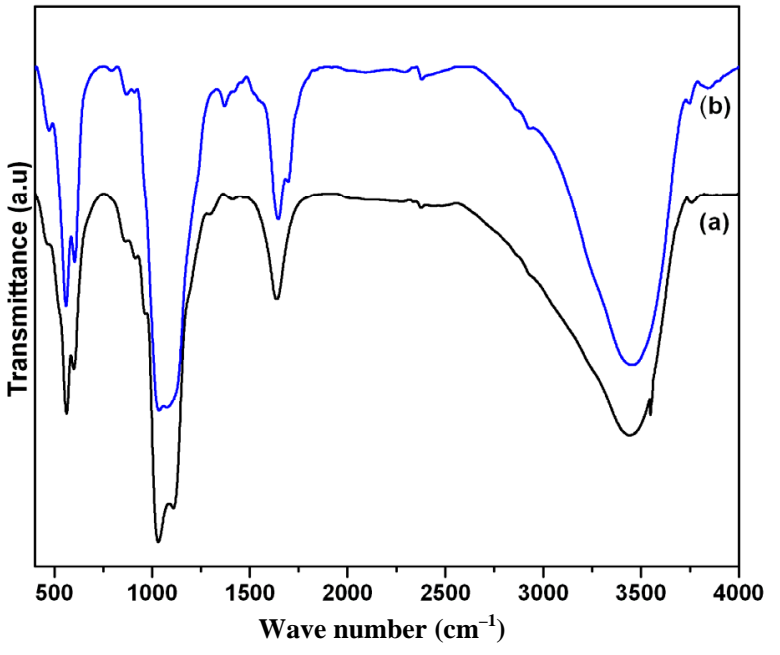

Figure 7. FTIR spectra of (a) BCP and (b) $0.1 \mathrm{M}$ Mg doped BCP.

BCP only $[25,26]$. The peak broadening of phosphate group and new peaks have confirmed the formation of tricalcium phosphate due to $\mathrm{Mg}$ doping.

\subsection{Nanoindentation Studies}

Mechanical behavior of the BCP samples was investigated in terms of hardness and elastic modulus obtained by nanoindentation. Figure 8 shows the typical loadpenetration depth $(p-h)$ curves obtained for BCP and Mg-BCP samples. For comparative analysis, the $p-h$ curve of $\mathrm{Sr}$ doped BCP is also incorporated [10]. In all the three cases, the $p$ - $h$ curves are associated with the displacement bursts or pop-ins as indicated by arrow marks in Figure 8. Similar pop-ins observed in the $p-h$ curves were reported to be associated with pile-ups around the indent mark for HA and $\beta$-TCP single crystals [27]. The mean value of elastic modulus $(E)$ and hardness values $(H)$ of $\mathrm{BCP}, \mathrm{Sr}$ and $\mathrm{Mg}$ doped $\mathrm{BCP}$ calculated from the $p$ - $h$ curves are shown in Table 3. It can be noticed that the $E$ and $H$ values for the Mg doped BCP is lower when compared to that of pure and $\mathrm{Sr}$ doped samples. The observed decrease in hardness values could be attributed to the enrichment of $\beta$-TCP phase and the difference in sizes between $\mathrm{Ca}(1.00 \AA)$ and the dopants $\operatorname{Sr}(1.13 \AA)$ and $\operatorname{Mg}(0.66 \AA)$. However, all the $p$ - $h$ curves show an elastic recovery after the removal of the applied load.

\section{Conclusion}

The Mg doped biphasic calcium phosphate was successfully synthesized by the simple gel method. The as prepared and sintered $\left(1000^{\circ} \mathrm{C}\right)$ samples did not indicate the presence of impurities like $\mathrm{CaO}, \mathrm{CaCO}_{3}, \mathrm{MgO}$ and nitrates. The presence of $\mathrm{Mg}^{2+}$ ions in the growth environ- 


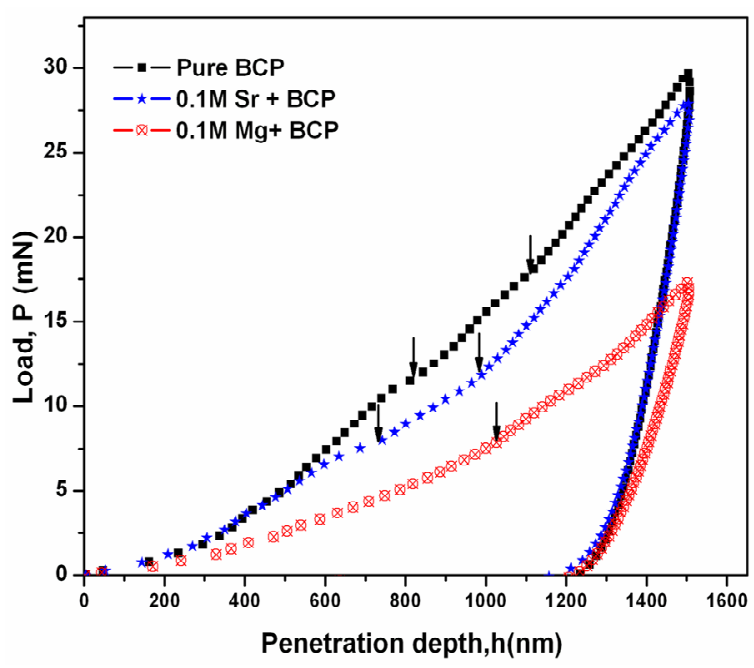

Figure 8. Load vs displacement curves of BCP, Sr and Mg doped BCP.

Table 3. The mean value of elastic modulus $(E)$ and hardness values $(H)$ of pure, Sr and Mg doped BCP calculated from the $p$ - $h$ curve.

\begin{tabular}{ccc}
\hline Sample & $\begin{array}{c}\text { Elastic modulus }(E) \\
(\mathrm{GPa})\end{array}$ & $\begin{array}{c}\text { Hardness }(H) \\
(\mathrm{GPa})\end{array}$ \\
\hline BCP & $23.41( \pm 3.14)$ & $0.613( \pm 0.107)$ \\
$\mathrm{BCP}+0.1 \mathrm{M} \mathrm{Sr}$ & $16.81( \pm 4.00)$ & $0.427( \pm 0.081)$ \\
$\mathrm{BCP}+0.1 \mathrm{M} \mathrm{Mg}$ & $10.64( \pm 2.24)$ & $0.349( \pm 0.100)$ \\
\hline
\end{tabular}

ment suppresses the nucleation and subsequent growth of BCP. Powder XRD results confirmed phase formation and the variation in HA/TCP content in BCP as a function of $\mathrm{Mg}$ in the starting compound. When compared to undoped $\mathrm{BCP}, \mathrm{Mg}-\mathrm{BCP}$ samples exhibited a higher proportion of $\beta$-TCP content. XRD and EDX analyses confirmed $\mathrm{Mg}$ doping into $\mathrm{BCP}$. The SEM micrographs showed that the microstructural morphology of BCP changes from fibrous for pristine $\mathrm{BCP}$ to agglomerates of fibers for $\mathrm{Mg}-\mathrm{BCP}$. The nanoindentation results revealed that the hardness $(H)$ and elastic modulus $(E)$ of BCP slightly decreases due to $\mathrm{Mg}$ doping. The in vitro bioactivity study showed that the $\mathrm{Mg}$ doped BCP could induce apatite formation on their surface after three weeks of soaking in simulated body fluid which is desirable for bone replacement applications.

\section{Acknowledgements}

P.K. acknowledges with thanks the Council of Scientific and Industrial Research (CSIR), India for providing the Research Associateship (F. No. 9/688(0022)/12 EMR-I).

\section{REFERENCES}

[1] S. Gomes, G. Renaudin, E. Jallot and J. M. Nedelec,
"Structural Characterization and Biological Fluid Interaction of Sol-Gel-Derived Mg-Substituted Biphasic Calcium Phosphate," Applied Materials and Interfaces, Vol. 1, No. 2, 2009, pp. 505-513. doi:10.1021/am800162a

[2] S. Mondal, B. Mondal, A. Dey and S. S. Mukhopadhyay, "Studies on Processing and Characterization of Hydroxyapatite Biomaterials from Different Bio Wastes," Journal of Minerals \& Materials Characterization \& Engineering, Vol. 11, No. 1, 2012, pp. 55-67.

[3] D. Luna-Zaragoza, E. T. Romero-Guzmán and L. R. Reyes-Gutiérrez, "Surface and Physicochemical Characterization of Phosphates Vivianite, $\mathrm{Fe}_{2}\left(\mathrm{PO}_{4}\right)_{3}$ and Hydroxyapatite, $\mathrm{Ca}_{5}\left(\mathrm{PO}_{4}\right)_{3} \mathrm{OH}$," Journal of Minerals \& Materials Characterization \& Engineering, Vol. 8, No. 8, 2009, pp. 591-609.

[4] R. W. N. Nilen and P. W. Richter, "The Thermal Stability of Hydroxyapatite in Biophasic Calcium Phosphate Ceramics," Journal of Minerals \& Materials Characterization \& Engineering, Vol. 19, No. 4, 2008, pp. 1693-1702. doi:10.1007/s10856-007-3252-X

[5] F. Ren, Y. Leng, R. Xin and X. Ge, "Synthesis, Characterization and $\mathrm{Ab}$ Initio Simulation of Magnesium-Substituted Hydroxyapatite," Acta Biomater, Vol. 6, No 7, 2010, pp. 2787-2796. doi:10.1016/j.actbio.2009.12.044

[6] I. Cacciotti, A. Bianco, M. Lombardi and L. Montanaro, "Mg-Substituted Hydroxyapatite Nanopowders: Synthesis, Thermal Stability and Sintering Behavior," Journal of the European Ceramic Society, Vol. 29, No. 14, 2009, pp. 2969-2978. doi:10.1016/j.jeurceramsoc.2009.04.038

[7] H. S. Ryu, K. S. Hong, J. K. Lee, D. J. Kim, J. H. Lee, B. S. Chang, D. H. Lee, C. K. Lee and S. S. Chung, "Magnesia-Doped HA $/ \beta$-TCP and Evaluation of Their Biocompatibility," Biomaterials, Vol. 25, No. 3, 2004, pp. 393-401. doi:10.1016/S0142-9612(03)00538-6

[8] S. Kannan and J. M. F. Ferreira, "Synthesis and Thermal Stability of Hydroxyapatite- $\beta$-Tricalcium Phosphate Composites with Cosubstituted Sodium, Magnesium, and Fluorine," Chemistry of Materials, Vol. 18, No. 1, 2006, pp. 198-203. doi:10.1021/cm051966i

[9] S. R. Kim, J. H. Lee, Y. T. Kim, D. H. Riu, S. J. Jung, Y. J. Lee, S. C. Chung and Y. H. Kim, "Synthesis of Si, Mg Substituted Hydroxyapatites and Their Sintering Behaviors," Biomaterials, Vol. 24, No. 8, 2003, pp. 1389-1398. doi:10.1016/S0142-9612(02)00523-9

[10] P. Kanchana and C. Sekar, "Influence of Strontium on the Synthesis and Surface Properties of Biphasic Calcium Phosphate (BCP) Bioceramics," Journal of Applied Biomaterials and Biomechanics, Vol. 8, No. 3, 2010, pp. 153-158.

[11] P. Kanchana and C. Sekar, "Influence of Sodium Fluoride on the Synthesis of Hydroxyapatite by Gel Method," Journal of Crystal Growth, Vol. 312, No. 6, 2010, pp. 808-816. doi:10.1016/j.jcrysgro.2009.12.032

[12] C. K. Chauhan, M. J. Joshi and A. D. B. Vaidya, "Growth Inhibition of Struvite Crystals in the Presence of Herbal Extract Boerhaavia Diffusa Linn," American Journal of Infectious Diseases, Vol. 5, No. 3, 2009, pp. 170-179. doi:10.3844/ajidsp.2009.170.179

[13] T. Kokubo, H. Takadama, "How Useful is SBF in Pre- 
dicting in Vivo Bone Bioactivity?" Biomaterials, Vol. 27, No. 15,2006 , pp. 2907-2915. doi:10.1016/j.biomaterials.2006.01.017

[14] W. C. Oliver and G. M. Pharr, "An Improved Technique for Determining Hardness and Elastic Modulus Using Load and Displacement Sensing Indentation Experiments," Journal of Materials Research, Vol. 7, No. 6, 1992, pp. 1564-1583. doi:10.1557/JMR.1992.1564

[15] J. F. Ferguson and P. L. McCarty, "Effects of Carbonate and Magnesium on Calcium Phosphate Precipitation," Environmental Science and Technology, Vol. 5, No. 6, 1971, pp. 534-540. doi:10.1021/es60053a005

[16] S. Veintemillas-Verdaguer, "Chemical Aspects of the Effects of Impurities in Crystal Growth," Progress in crystal growth and characterization of materials, Vol. 32, No. 1-2, 1996, pp. 75-109. doi:10.1016/0960-8974(96)00005-8

[17] E. Boanini, M.Gazzano and A. Bigi, "Ionic Substitutions in Calcium Phosphates Synthesized at Low Temperature," Acta Biomaterialia, Vol. 6, No. 6, 2010, pp. 18821894. doi:10.1016/j.actbio.2009.12.041

[18] A. Bigi, M. Gazzano, A. Ripamonti and N. Roveri, "Effect of Foreign Ions on the Conversion of Brushite and Octacalcium Phosphate into Hydroxyapatite," Journal of inorganic biochemistry, Vol. 32, No. 4, 1988, pp. 251-257. doi:10.1016/0162-0134(88)85004-9

[19] M. H. Salami, J. C. Heughebaert and G. H. Nancollas, "Crystal Growth of Calcium Phosphates in the Presence of Magnesium Ions.” Langmuir, Vol. 1, No. 1, 1985, pp. 119-122. doi:10.1021/1a00061a019

[20] E. C. Victoria and F. D. Gnanam, "Synthesis and Characterization of Biphasic Calcium Phosphate," Trends in Biomaterials \& Artificial Organs, Vol. 16, No. 1, 2002, pp. 12-14.
[21] W. L. Suchanek, K. Byrappa, P. Shuk, R. E. Riman, V. F. Janas and K. S. Ten Huisen, "Mechanochemical-Hydrothermal Synthesis of Calcium Phosphate Powders with Coupled Magnesium and Carbonate Substitution," Journal of solid state chemistry, Vol. 177, No. 3, 2004, pp. 793-799. doi:10.1016/i.jssc.2003.09.012

[22] P. N. Kumta, C. Sfeir, D. H. Lee, D. Olton and D. Choi, "Nanostructured Calcium Phosphates for Biomedical Applications: Novel Synthesis and Characterization," Acta Biomaterialia, Vol.1, No. 1, 2005,pp. 65-83. doi:10.1016/j.actbio.2004.09.008

[23] I. Sopyan and A. N. Natasha, "Preparation of Nanostructured Manganese-Doped Biphasic Calcium Phosphate Powders via Sol-Gel Method," Ionics, Vol. 15, No. 62009, pp. 735-741. doi:10.1007/s11581-009-0330-8

[24] I. Manjubala and M. Sivakumar, "In-Situ Synthesis of Biphasic Calcium Phosphate Using Microwave Irradiation," Materials Chemistry and Physics, Vol. 71, No. 3, 2001, pp. 272-278. doi:10.1016/S0254-0584(01)00293-0

[25] J. Pena and M. Vallet-Regi, "Hydroxyapatite, Tricalcium Phosphate and Biphasic Materials Prepared by a Liquid Mix Technique," Journal of the European Ceramic Society, Vol. 23, No. 10, 2003, pp. 1687-1696. doi:10.1016/S0955-2219(02)00369-2

[26] K. P. Sanosh, M. C. Chu, A. Balakrishnan, T. N. Kim, S. J. Cho, "Sol-Gel Synthesis of Pure Nano Sized $\beta$-Tricalcium Phosphate Crystalline Powders," Current Applied Physics, Vol. 10, No. 1, 2010, pp. 68-71. doi:10.1016/j.cap.2009.04.014

[27] B. Viswanath, R. Raghavan, U. Ramamurthy and N. Ravishankar, "Mechanical Properties and Anisotropy in Hydroxyapatite Single Crystal," Scripta Materialia, Vol. 57, No. 4, pp. 361-364. doi:10.1016/i.scriptamat.2007.04.027 